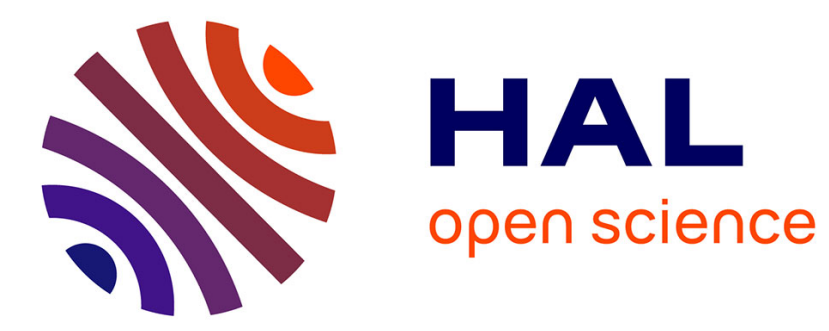

\title{
Preliminary study of rescue systems for Mars landing
} Jean-Marc Salotti, Julien Doche

\section{To cite this version:}

Jean-Marc Salotti, Julien Doche. Preliminary study of rescue systems for Mars landing. Acta Astronautica, 2021, 188, pp.81-88. 10.1016/j.actaastro.2021.07.017 . hal-03441041

\section{HAL Id: hal-03441041 \\ https://hal.science/hal-03441041}

Submitted on 23 Nov 2021

HAL is a multi-disciplinary open access archive for the deposit and dissemination of scientific research documents, whether they are published or not. The documents may come from teaching and research institutions in France or abroad, or from public or private research centers.
L'archive ouverte pluridisciplinaire HAL, est destinée au dépôt et à la diffusion de documents scientifiques de niveau recherche, publiés ou non, émanant des établissements d'enseignement et de recherche français ou étrangers, des laboratoires publics ou privés. 


\title{
RESCUE SYSTEMS FOR MARS LANDING
}

\author{
Jean-Marc Salotti ${ }^{a, b, c, d}$ and Julien Doche ${ }^{d}$ \\ a Univ.Bordeaux, CNRS, Bordeaux INP, IMS, UMR 5218, F-33400, Talence, France, jean-marc.salotti@ensc.fr \\ b INRIA, IMS, UMR 5218, F-33400, Talence, France \\ ${ }^{c}$ Association Planète Mars, France \\ ${ }^{d}$ Ecole Nationale Supérieure de Cognitique, Bordeaux INP, France
}

\begin{abstract}
Entry, descent and landing (EDL) is probably the most difficult and risky phase of a human mission to Mars. Whatever the EDL systems for Mars, the qualification might be very difficult, very expensive and the risks could still be very high, especially for the first missions. Risks could nevertheless be mitigated if backup options existed during the final phase of EDL. If an important problem is encountered during the last minutes of the descent and if the velocity is lower than Mach 3, a possible option is to use an ejection seat, an individual parachute and small thrusters, which could be attached to the seat of the astronaut. The total mass of such a rescue system would be of the order of $230 \mathrm{~kg}$, which does not include the mass of the astronaut. In the event of an emergency landing, the astronaut will still have to reach a safe haven quickly to survive because of his limited life support system autonomy. An automatic rover can be sent to rescue the astronaut and increase the maximum rescuing distance. A probabilistic risk assessment has been performed. Provided that the autonomy of the life support system is eight hours and that there is no insurmountable obstacle, it is shown that the probability of reachability is 0.9 at $50 \mathrm{~km}$ from the safe haven.
\end{abstract}

Keywords: Entry, descent and landing, backup strategies, landing risks.

\section{Introduction}

As entry, descent and landing (EDL) on Mars is one of the most dangerous phases of a human mission to Mars, is it necessary to integrate back-up systems to reduce the risk of losing astronauts $[1,2,3]$ ? On Earth, the launch and access to orbit phases, which require heavy and complex propulsion systems are considered very risky. In order to mitigate the risks, the human rated qualification rule is to provide an emergency evacuation system that can be triggered at any time for a safe return to the ground under parachutes. For the return fromEarth orbit, no emergency system is available, apart from the redundancy of the parachutes, but there is however no need for a propulsion system (except during the last second for the final cushioning). As the atmosphere of Mars is much thinner than Earth's, a propulsive phase is required for the last braking and, as the surface is irregular, the propulsive phase might involve lateral moves as was the case for the Apollo 11 mission to the Moon. The complexity of the EDL phase for Mars is therefore much greater than Earth's and the inclusion of a backup system for landing is an important issue. A possible solution is to impose a constraint on the architecture of the mission, such that the stay on the surface is relatively short and the crewed descent vehicle includes a fully fuelled Mars ascent vehicle [4,5]. A NASA team proposed another solution with a single-stage reusable vehicle called Hercules [6]. These strategies allow an abort to orbit mode. In addition, if the crew is embedded in a small capsule with its own propulsion capabilities, an abort to surface mode is also possible [6]. If these constraints are not accepted, it is difficult to implement abort options without important mass penalties, which could imply additional heavy launches from Earth and complex LEO assembly operations. Any backup system must be very light to be acceptable. Interestingly, during Gemini missions, astronauts were equipped with a parachute and could eject [7]. Likewise, when the Hermès shuttle was designed, seat ejection systems were planned, similar to those used for military airplanes [8,9]. Is it possible to use ejection seats for Mars landings? And if yes, what would be the conditions of use and the requirements for complementary systems allowing safe landing and survival after landing? These questions are addressedin the following sections. In section 2, the risks of the EDL phase are summarised. Section 3 is dedicated to the constraints and conditions that have to be fulfilled to enable the rescue of the astronauts. Different rescue systems are proposed and discussed in Section 4 and the main conclusions are given in the final section.

\section{EDL risks}

Numerous robotic missions have been implemented for the exploration of the surface of Mars. Many have been successful (Viking, Pathfinder, Mer, Phenix, Curiosity, Insight), but many others failed to reach the surface at the very end of the mission, due to a problem encountered during the EDL phase, see Table 1. 
Table 1: Numerous missions failed during the descent to the Martian surface.

\begin{tabular}{|l|l|}
\hline Mars mission & Failure mode \\
\hline Mars 2 & Parachute not deployed \\
\hline Mars 6 & Contact lost during descent \\
\hline Mars 7 & Retrorocket failure \\
\hline Mars polar lander & Contact lost during descent \\
\hline Beagle 2 & Contact lost during descent \\
\hline Schiaparelli & $\begin{array}{l}\text { Wrong interpretation of sensors } \\
\text { data during last phase of descent }\end{array}$ \\
\hline
\end{tabular}

If EDL risks are considered very high for robotic missions, it could be even worse for human missions. Many authors highlighted these risks, explaining that landing heavy vehicles on Mars is more challenging than landing light vehicles $[1,2,3,10,11,12,13]$. There are several reasons for this:

- The ballistic coefficient is in general higher for heavy vehicles, which means that atmospheric braking is less efficient.

- As the use of gigantic parachutes would be impractical, different EDL systems must be considered for heavy vehicles, for instance giant inflatable heat shields [14], with a low Technology Readiness Level.

- If very large diameter heat shields are required (perhaps two heat shields, one for the hypersonic and another for the supersonic regime), a complex deployment procedure would need to be carried out.

- At the end of the atmospheric braking phase, heat shields may have to be ejected, which might be difficult.

- After heat shield ejection, the vehicle must be reoriented in a very short time so that the thrust direction is opposed to the speed direction. This manoeuvre is more difficult and takes longer for large vehicles.

- For the final propulsion phase, multiple rocket engines have to be fired at supersonic regime.

- The velocity and the landing position must be controlled with greater accuracy.

All in all, according to NASA, EDL risks are considered a major concern of human missions to Mars and the best option remains to be determined $[11,14]$.

\section{Top level functions}

\subsection{Main principles}

The rescue system must be composed of four major subsystems, the evacuation system (ES), the descent and landing system (DLS), the surface rescue system (SRS) and the communication system(CS). The top level functions are:

F1: Phase 1, evacuation: Use the ES to rapidly evacuate the astronauts from the spacecraft.

F2: Phase 2a, descent: Use the DLS to provide an alternative and safe descent system to reach the surface (it is assumed that coming back to orbit is practically impossible).

F3: Phase 2b, landing: Use the DLS to provide a physiologically safe landing, including lateral adjustments to avoid dangerous zones (e.g. edge of a cliff).

F4: Phase 2c, exit: Provide a safe exit from the DLS.

F5: Phase 3, surface mobility: Use the SRS to provide transportation means to the astronauts once landed on the surface, so that they can reach a safe haven.

F6: Phase 2 and 3, life support: Provide a life support system during the descent and on the surface for a minimum duration of at least 8 hours (to be discussed). This life support system may be associated to the DLS or SRS, or both. 
F7: Phase 3, communication: Use the CS to provide communication capabilities with mission control, and all other astronauts in the mission and any other automatic system involved in the rescue (SRS) in order to define and share the best rescue strategy.

F8: Phase 3, navigation: Provide navigation capabilities to the astronaut, position and orientation, to determine the direction and distance of the closest safe haven.

F9: Phase 4, safe haven. Complementary assets must be present on the surface in order to carry on or abort the mission safely, eventually with restrictive operational conditions (to be discussed). In particular, a habitable module must be present on the surface before the arrival of the astronauts. It is an important element of the SRS.

In addition, the rescue system on board the landing vehicle (ES and DLS) must be as simple and light as possible, to avoid the complexification of the primary EDL system and the complexification of the mission architecture.

\subsection{Assessment of the differentoptions}

Several options are possible for the evacuation and descent and landing systems (ES and DLS):

1) Ejection of a small vehicle (capsule): As is proposed for take-off from Earth, all astronauts can be placed in a small capsule that can be ejectedin an emergency procedure, thanks to pyrotechnic systems and a propulsion system. However, even if a parachute could help braking before landing, as the density of the atmosphere is very low, it would not be sufficient to reduce the velocity to acceptable levels and to land safely on Mars. A heavy propulsion system would thus be required, which would be a serious mass penalty for the vehicle and a handicap for the design of the primary EDL system. As this is contrary to our recommendations, another option would be preferable.

2) Ejection seat with spacesuit and parachute [9]: This option has already been implemented for the Vostok and the Gemini programs (see Fig. 1). It was also considered and validated for the European Hermes shuttle, which remained a concept study [8]. For Mars, the idea is to trigger a pyrotechnic system that would open the wall of the space vehicle and allow the ejection of the astronauts on their seats. Importantly, implementing that ejection system will require the crew to land in an EVA-ready suit, portable life support system included, eventually not on their back but attached to the seat. Such an option would be viable during a short window of time at the end of the atmospheric braking, when the vehicle has been slowed down to acceptable velocities. Once ejected, a parachute immediately opens and progressively reduces the speed of the astronaut. On Earth, thanks to appropriate parachute systems (disk gap band parachute), ejection seats can be used at very high velocities, typically around Mach 1 at sea level. On Mars, as atmospheric pressure is much lower, parachutes could be opened at much higher velocities. According to Braun and Manning, on Mars, taking thermal constraints into account, it would be possible to use parachutes at Mach 2.7 or even Mach 3 [1]. On Earth, the final (and relatively safe) velocity of a parachutist is between 5 and $8 \mathrm{~m} / \mathrm{s}$. On Mars, even if very large parachutes were used, the final falling velocity would be around $50 \mathrm{~m} / \mathrm{s}$, which would kill the astronaut at impact. Another system is therefore required to reduce the velocity at touch down. Three main options are possible for the landing subsystem of the DLS:

a. Airbag: An inflatable system could absorb the energy at impact. However, if the final descent velocity is of the order of $50 \mathrm{~m} / \mathrm{s}$, it must be very large to reduce accelerations to acceptable physiological levels. For instance, if the maximum allowed acceleration is $10 \mathrm{~g}$, the airbag must be at least 12.5 metres high, which is impractical. This option is rejected.

b. Backpack jetpack: If backpack jetpacks are used, the astronauts land on their feet. The thrusters of the jetpack can be controlled in an automatic way. However, after an interplanetary flight without gravity, it is doubtful that the astronauts could easily stand on the surface. In addition, the trauma of the ejection might cause a loss of consciousness, which would be dangerous in case of landing in a standing position. This option is therefore also rejected.

c. Ejection seat equipped with thrusters: The astronaut remains in the seat until touch down. Small thrusters are positioned under the seat. After ejection, a parachute is used for the main braking phase. Then thrusters are used at the very end of the descent to land softly on the surface.

d. Same as option c, but a skycrane is used: This technology was justified by NASA to facilitate the deployment of rovers on the surface of Mars (e.g., Curiosity). There was indeed no need to add a descent platform and the ground was not impacted by the exhaust of the thrusters. However, in the 
context of the rescue system, there is no clear advantage for a skycrane, which is complex to deploy and not the lighter option.

Option $2 \mathrm{c}$ is therefore the preferred option. This concept is illustrated in Fig.2.

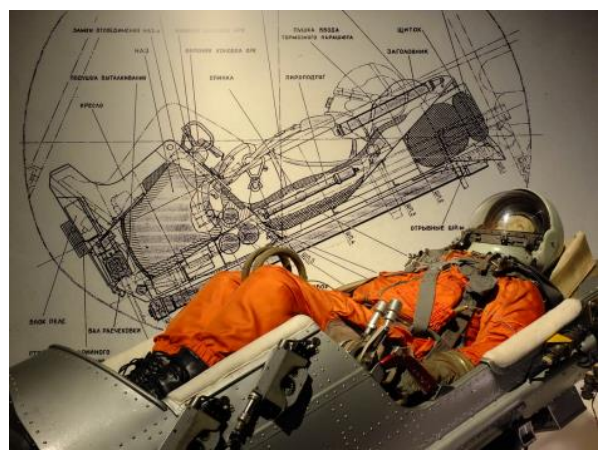

Fig. 1. Vostok ejection seat (licence: Creative Commons).

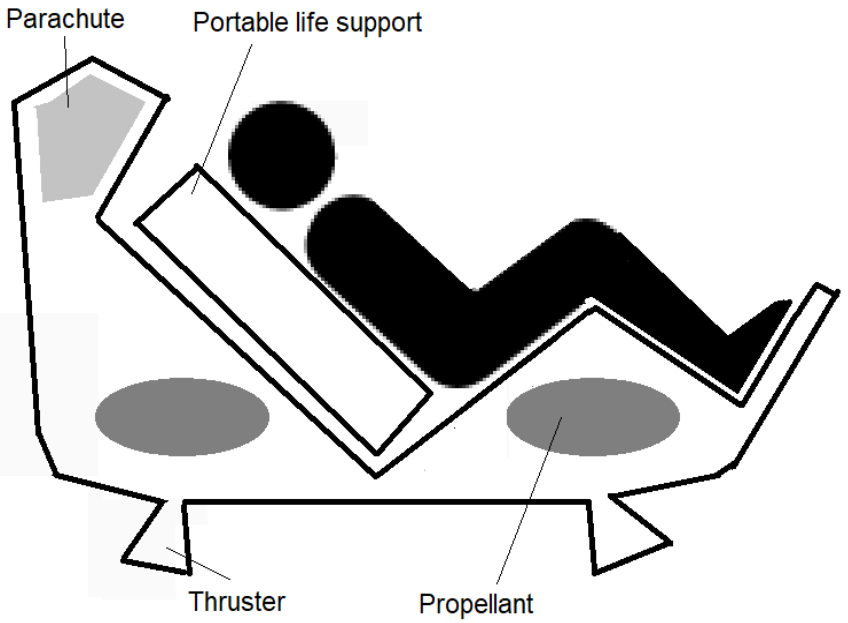

Fig. 2. Ejection seat concept.

\subsection{After landing}

Once on the surface, it is the role of the SRS to rescue the astronauts. Other resources should be available, such as a habitable module to make sure that the astronauts can reach a safe haven. In most Mars mission architectures, such a habitable module is indeed pre-positioned on Mars before the astronauts' arrival [13-16]. In nominal conditions, there is an accurate control of the descent and the landing ellipse is of the order of 10 kilometres large at the end of the aerodynamic braking [17]. According to a NASA study, a lateral displacement of a few kilometres is planned to reach the base in a precise way [14]. If the descent goes badly, but the navigation is correct, the distance of the landing site is thus of the order of $10 \mathrm{~km}$, which seems feasible walking. If on the other hand the navigation is affected, the distance can be enormous, which would certainly condemn the survival astronauts. It is assumed in the following that a habitable module is already present on the surface and is a fundamental element of any rescue system.

There are three transportation options to reach the habitable module:

1) Astronaut walking. After several months in $0 \mathrm{~g}$, without countermeasures, the crew members will be deconditioned and will have difficulties standing and walking. This is a well-known problem and two options are generally considered to avoid or mitigate the effects. The first is a simulation of the gravity by a permanent rotation of two modules and the second is the daily use of a small centrifuge [18]. Whatever the option, the astronauts will use exercise machines to stay fit. It is therefore expected that the crew members will still have some walking capabilities upon arrival, though probably less than nominal as a period of sensorimotor adaptation might also be required. An important issue is the adaptation of the spacesuit to long distance walking. Several spacesuit designs are currently investigated at NASA [19,20]. Operational tests will determine the physical and cognitive effects of 3x8 hour simulated planetary EVA in a week. Such spacesuits 
are nevertheless heavy and not optimized for walking. Another concept, the bio-suit, might be more appropriate [21]. On Earth, the walking speed can be as high as $5.5 \mathrm{~km} / \mathrm{h}$ without much effort. Some research suggests that the optimum walking speed on Mars would be around $3.4 \mathrm{~km} / \mathrm{h}$ [22]. This optimum is lower on Mars because it takes more time for the centre of mass to come down and therefore for the front foot to come back to the ground. However, as the mass of the astronaut would be lower on Mars, even wearing a spacesuit, an adaptive walk or a fast walk would certainly be easier on Mars than on Earth. Aldrin reported, for instance for the Moon, that walking like we do on Earth was not efficient but that he was able to make small jumps and to reach 5 to 6 miles per hour without effort [23]. During extra-vehicular activity outside the International Space Station, the autonomy of life support systems is limited by lithium hydroxide canisters for the removal of carbon dioxide. Future technologies might provide an autonomy of 8 hours [20,24]. Providing that an effort is made to mitigate $0 \mathrm{~g}$ effects and to adapt the spacesuit, walking would be the first option to reach the habitable module $[18,25,26]$. This is however not possible if the module is too far. Another option must be preferred for adapting to a greater number of possible situations.

2) The seat is equipped with wheels and is transformed into an unpressurized rover. This option is possible, but it increases the mass of the rescue system and there is no guarantee that, first, the landing zone allows driving a rover (imagine a scree) and, secondly, that a safe path exists towards the habitable module (no impassable obstacle, e.g., landing on the other side of a very long and deep canyon).

3) A vehicle is present near the habitat and is used to bring the astronauts back to it. Importantly, at least for the first missions to Mars, it is expected that there will be no rescue team on the surface. As a consequence, any rescue vehicle must be automatically deployed and remotely driven towards the landing zone.

Option 3) is the preferred option. Several categories of vehicle can be used for the rescue: pressurised or not, fully automatic, remotely controlled, or possibly with the two operating modes, depending on the context. According to a previous study, the choice between a pressurised rover and an unpressurised one (or several unpressurised rovers if there are several astronauts) is difficult, see Table $2[27,28]$. According to our assessment, both options provide acceptable rescue solutions. The choice could be in fact made according to criteria linked to the scientific objectives of the mission. The only constraint is to have the vehicle(s) deployed on the surface ready for a rescue before the arrival of the astronauts.

Table 2. Assessment of the type of vehicle.

\begin{tabular}{|l|l|l|l|l|l|}
\hline & $\begin{array}{l}\text { Automatic } \\
\text { deployment } \\
\text { on the surface }\end{array}$ & $\begin{array}{l}\text { Long distance range } \\
\mathbf{( > 1 0 0 ~ k m ) ~}\end{array}$ & $\begin{array}{l}\text { Terrain } \\
\text { adaptability }\end{array}$ & Weight & Life support \\
\hline Pressurised & Complex & Yes, but risky. & $\begin{array}{l}\text { Average. Low in } \\
\text { mountains. }\end{array}$ & Heavy & $\begin{array}{l}\text { Yes, with } \\
\text { medical } \\
\text { emergency } \\
\text { capabilities }\end{array}$ \\
\hline Unpressurised & Simple & $\begin{array}{l}\text { Yes, provided that it is } \\
\text { equipped with a } \\
\text { deployablent and } \\
\text { life support systems. } \\
\text { To be discussed. }\end{array}$ & $\begin{array}{l}\text { Average. Low in } \\
\text { mountains. }\end{array}$ & Light & $\begin{array}{l}\text { No, or with } \\
\text { simple life } \\
\text { support (O2) }\end{array}$ \\
\hline
\end{tabular}

Regarding the operating mode, the best trade-off could be automatic as long as the astronaut does not take control of the vehicle and command it remotely.

\subsection{Life support system}

The astronauts must wear an EVA-suit equipped with a life support system. After landing, the astronauts would have to leave their seat. It is conceivable that among the elements making up the ejection system is a module that can be pressurised (this can take a simple form such as a tent). With the help of this shelter, if the astronauts can remove their suit, they will be able to repair it more easily but also to care for themselves and replace various essential elements of the suits, such as oxygen reserves and carbon dioxide filters. The pressurised shelter also provides water and food supplies outside the suit. Depending on the complexity of the pressurised module, it can be used to manage temperature variations. Indeed, the temperature variations on the surface of Mars are important, going from $-125^{\circ} \mathrm{C}$ to $+20^{\circ} \mathrm{C}$. 
Without this additional pressurised space, the astronauts have to rely solely on the resources of the life support systems attached to the suits. NASA is currently designing and testing EVA-suits for the Moon and Mars with an autonomy of 8 hours [20]. If the suits used on Mars evolve, with significant improvements on the astronaut's mobility and the quality of the communication systems, the oxygen autonomy should remain similar due to constraints on the size and mass of the reserves. The only accessible food and water reserves are those already present in the suit. Healing and repairing are also more difficult.

Whether or not a base is already present on Mars with other astronauts, communicating with the habitable module and the rescue vehicle(s) is fundamental. Thus, in order to maximize the survival probability, the evacuation seat must contain a radio communication system to be able to start the rescue procedure with the vehicles. In case of injuries during the descent and landing on Mars, the crew will have to wait for the rescue vehicle to get some medical equipment.

In any case, the life expectancy of the astronauts in such conditions is rather low and can be counted in tens of hours maximum.

\subsection{Feedback and choice}

Astronauts can reach the base only if they have the ability to move sufficiently, in the right direction and in the time allowed by their resources. Depending on their propensity to evaluate these dimensions, the astronauts will have to make a choice between two options:

- In general, the best option for the astronauts will be to stay at the landing site to take care of themselves and wait for the rescue vehicle. However, there are many situations where the vehicle is not able to reach the exact landing position or the time to get there is uncertain, or the reliability of the AI system is unsure. Numerous tests will have to be performed to assess the performance and robustness of that choice.

- Try to reach the base or the vehicle. This is possible only if $0 \mathrm{~g}$ effects have been mitigated, if the EVA-suit allows efficient walking and if the astronaut is in good shape.

In view of his central role, special attention must be paid to developing feedback on the three following elements:

Resources: Oxygen reserves, oxygen consumption rate, remaining time until loss of $\mathrm{CO} 2$ removal effectiveness, and battery lifetime, in particular. The interface of the suit may provide all needed information. In addition, part of the training must include the use of these systems and a simulation of an emergency situation.

Navigation system: Ideally a GPS-type tool can provide the astronaut with a map with geological cues, the position of the astronaut(s) as well as the directions and positions of the habitable module and the rescue vehicle(s). The position of the astronaut can be calculated by a satellite receiving a pulse signal emitted by a system attached to the spacesuit of the astronaut. Different options are possible. Several satellites can triangulate the position or a single satellite can infer the position by means of Doppler measurements (also used on Earth). However, several satellites must be orbiting at the same time to make sure that one of them is still present above while the others are behind the planet. Instead of a satellite, another space vehicle can be used. Remarkably, an areosynchronous orbit is proposed for the Earth return vehicle of several Mars mission architectures [12,15]. This space vehicle cannot be used for accurate measurements as it would be too far from the planet. On the other hand, it could be the main vehicle for a communication relay to transfer information between the various players: the satellites, Mission control onEarth, the surface rescue vehicle(s), the astronaut(s) and maybe other assets on the surface. In case of communication problems or if the use of a satellite is not possible, the astronaut must pay attention to the last position of the landing module before triggering the ejection seat. Then an inertial unit attached to the ejection seat can provide complementary information about the final position on the surface. This information is very important as it can be used by the astronaut to determine his position. Nevertheless, the position is not sufficient, as the astronaut must be able to orient himself using a map and geological cues, the position of the sun (or stars by night). This is not an easy task. A dedicated system and a detailed procedure must be provided. Concerning the rescue vehicle, it must be ready to move by a simple command from the astronaut (through space communication relay). In case of communication problems, the command could come from Earth. Then artificial intelligence systems must be used on board the rescue vehicle to determine the best path to come as close as possible to the astronaut, taking obstacles into account. Once the signal from the vehicle can be detected by the astronaut's receiver, and vice versa, direction finding systems (based on the strength of the signal) can be used to determine the direction of movement with more accuracy [29]. 
The ability to move: This is a difficult dimension to quantify, and the astronaut is the one able to make this estimate. Refining this skill is one of the challenges of training, knowing that the context (gravity and fitness) during training will necessarily be different on Mars.

It is likely that the choice will be a luxury that the astronauts do not have if the base is too far away or if they cannot move after landing. However, if they have this possibility, it is important to provide a decision aid. Indeed, the astronauts' decision-making ability may be strongly affected by many factors (such as stress, pain and fatigue). Perhaps the software detailing the available resources can include this decision support. If the astronauts are able to establish contact with the base by radio, they may also find guidance and comfort. In this case, a detailed map of the landing area may be important to help the astronauts find their way around.

\section{Rescue system for landing}

It is proposed here to follow a similar final landing sequence to that of the Insight mission [30]:

- The ejection seat slows down under a disk gap band parachute.

- At one kilometre altitude (a dedicated sensor is used for real time measurements of the altitude), the velocity is around $60 \mathrm{~m} / \mathrm{s}$ and it is the moment for parachute ejection and thruster ignition. Remark: As the seat can be ejected at lower altitudes, the velocity can be higher. The thrust has to be adapted to the situation.

- Provided that there is still some time before impact, the velocity is decreased to reach $5 \mathrm{~m} / \mathrm{s}$ at 30 metres above the surface.

- The velocity is decreased to reach $1 \mathrm{~m} / \mathrm{s}$ at 5 metres above the surface (it was $2.2 \mathrm{~m} / \mathrm{s}$ for Insight).

- The velocity is kept constant until the surface is reached about 5 seconds later.

- Thrusters are turned off at touchdown.

- Automatic rovers are sent to the landing site to rescue the astronauts.

Importantly, if the seat is ejected very late, the survival of the astronaut would depend on the maximum thrust of the engines and the human ability to support the load of the acceleration. In NASA reference missions, a $4 \mathrm{G}$ acceleration is mentioned as a maximum for the design of the EDL systems [14]. It is proposed here to use this constraint to determine the limits of the initial conditions to have enough time for slowing down before reaching the surface. Assuming a constant $4 \mathrm{G}$ deceleration using the thrust of the engines, the minimum altitude only depends on the initial falling velocity. This is defined by equation 1 and is plotted in Fig. 3.

$$
A l t_{\text {min }}=-0.5\left(a-G_{m}\right) t^{2}+V_{0} t
$$

With a: engine acceleration

$\mathrm{G}_{\mathrm{m}}$ : Martian gravity

$\mathrm{V}_{0}$ : Initial velocity

Alt $t_{\min }$ : Minimum altitude to avoid the crash

$t=\frac{V_{0}}{\left(a-G_{m}\right)}:$ Required time to reach the ground with $\mathrm{V}=0$ 


\section{Alt. $(\mathrm{km})$ Minimum altitude for seat ejection}

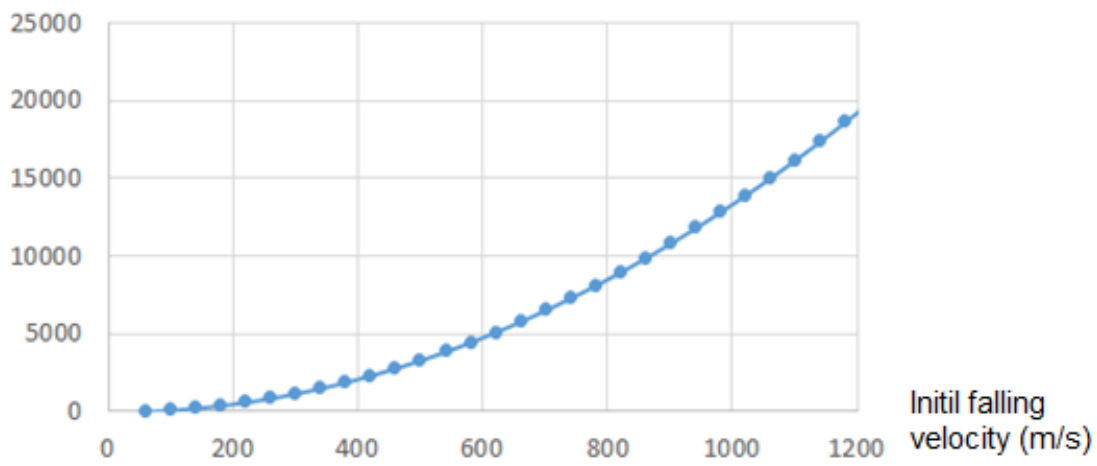

Fig. 3. Minimum altitude for seat ejection (vertical axis in metres) as a function of initial falling velocity (horizontal axis in $\mathrm{m} / \mathrm{s}$ ).

The horizontal velocity is not taken into account in the previous calculation. It is nevertheless considered in the maximum $4 \mathrm{G}$ tolerance. Let us assume that Mach 3 is the maximum viable velocity for triggering the ejection of the seat. Two cases have to be examined, with or without parachute:

- Without parachute, provided that the altitude is high enough, starting at $1020 \mathrm{~m} / \mathrm{s}$ (Mach 3), the $4 \mathrm{G}$ deceleration would last 32 seconds to slow the vehicle down to 0 . This duration can be used to determine the maximum amount of propellant required for the descent. Assuming a specific impulse of 230 seconds (based on the thruster used for the terminal descent of the Insight mission [31]) and a landing mass of $310 \mathrm{~kg}$ (see Table 3), the mass of propellant is given by equation 2 (derived from Tsiolkovsky equation) and would be equal to $177 \mathrm{~kg}$.

- Using a parachute, the deceleration would not be linear. Let us assume that it would nevertheless be acceptable in the worst case scenario, at least until Mach 1 is reached $(340 \mathrm{~m} / \mathrm{s})$. Then, using thrusters for the terminal braking phase, $50 \mathrm{~kg}$ of propellant would be enough if the thrust is optimized (equation 2), $60 \mathrm{~kg}$ with margins. As a parachute is a light device, the parachute option is therefore much lighter than the all-propulsive one.

$$
m_{p}=m_{f}\left(e^{\frac{\Delta v}{g_{0} I_{s p}}}-1\right)
$$

With $\mathrm{m}_{\mathrm{p}}$ mass of propellant, $\mathrm{m}_{\mathrm{f}}$ final mass, $\mathrm{I}_{\mathrm{sp}}$ specific impulse and $\Delta \mathrm{V}$ the velocity change requirement.

Table 3: Mass budget.

\begin{tabular}{|c|c|c|}
\hline \multicolumn{2}{|c|}{ Astronaut } & $80 \mathrm{~kg}$ \\
\hline \multirow{3}{*}{$\begin{array}{l}\text { Spacesuit, LSS included } \\
\text { Rescue } \\
\text { system }\end{array}$} & $\begin{array}{c}\text { Ejection seat (pyrotechnic } \\
\text { system not included) }\end{array}$ & $60 \mathrm{~kg}$ \\
\cline { 2 - 3 } & Parachute & $70 \mathrm{~kg}$ \\
\cline { 2 - 3 } & Landing legs & $20 \mathrm{~kg}$ \\
\cline { 2 - 3 } & Propulsion system (dry) & $50 \mathrm{~kg}$ \\
\cline { 2 - 3 } & Propellant & $60 \mathrm{~kg}$ \\
\cline { 2 - 3 } & Margins (10 \%) & $20 \mathrm{~kg}$ \\
\cline { 2 - 3 } & Total & $230 \mathrm{~kg}$ \\
\hline \multicolumn{2}{|c|}{ Total landed mass (w/o propellant) } & $310 \mathrm{~kg}$ \\
\hline
\end{tabular}


As the mass is a critical parameter, the parachute option is proposed here. In order to minimise the risks of tilting at touchdown, the seat can be equipped with legs that would be deployed during the descent. The total mass of the rescue system - seat, parachute, thrusters and propellant - would be around $230 \mathrm{~kg}$, about $370 \mathrm{~kg}$ with the astronaut and $310 \mathrm{~kg}$ for the landing mass. See Table 3 for a detailed budget mass and Fig. 4 for an estimation of the mass of the rescue system as a function of the mass of the spacesuit. Importantly, as a seat would be needed anyway, the additional mass for the DLS would be less, about $200 \mathrm{~kg}$ per astronaut. Another mass penalty should nevertheless be taken into account for the ejection system and eventually for the reorganization of the architecture of the habitable module, which is not discussed here.

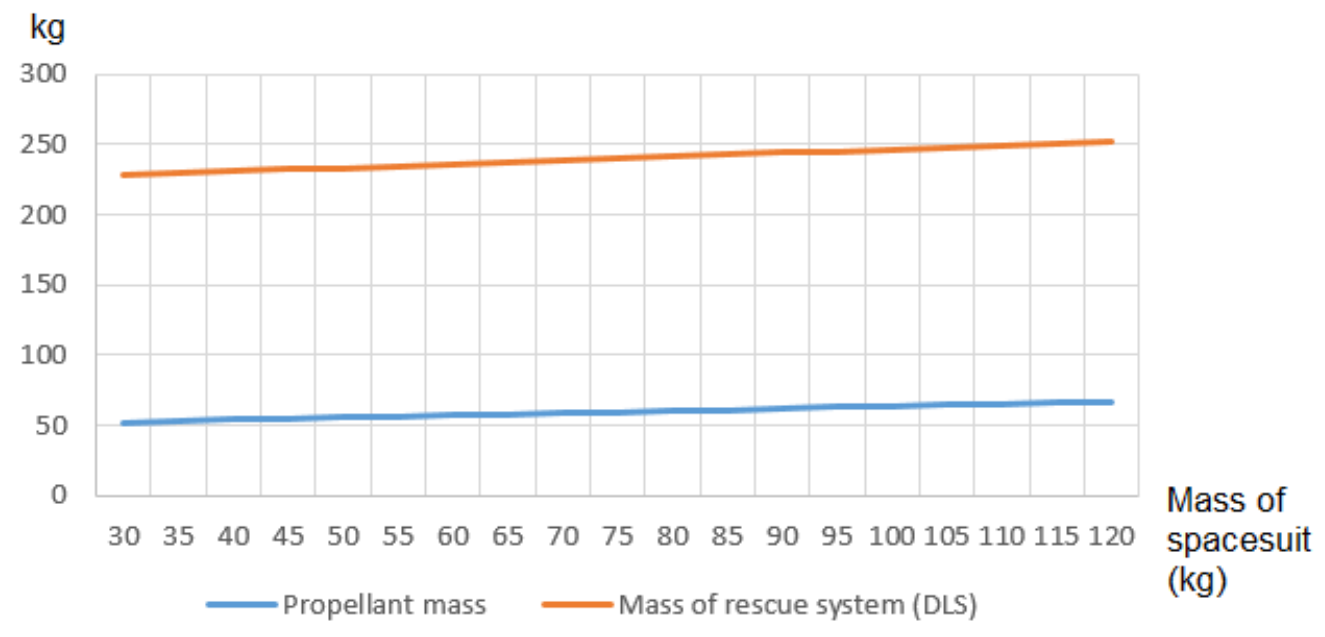

Fig. 4. Mass of propellant and rescue system as a function of the spacesuit mass.

\section{Probability risk assessment for a safe rescue using an autonomous vehicle}

Let us consider that all astronauts safely land on the surface of Mars, what is the probability that they reach a safe haven in time? The main parameters are the autonomy of the spacesuit, the average walking speed, the distance to the base, the autonomy of the autonomous vehicle and its average speed, which depends on several other parameters such as the capacity of the engine, the type of terrain, the presence of obstacles and the performance of the automatic piloting system. Let us assume that the autonomy of the spacesuit is 8 hours and that the automated vehicle brings enough fuel and life support for a safe return.

An important question is the ability for the vehicles and the astronauts to cross obstacles. In general, however, the landing site is chosen in relatively flat regions, which reduces the risk of being blocked by obstacles. Regardless of possible insurmountable obstacles or accidents, the probability of reachability can be estimated. If the expectation of the average walking speed is $\mathrm{v}$, the expectation of the maximum walking distance is $8 \mathrm{v}$. A simple way to define a distribution function for that distance is to use a Gaussian distribution $N_{1}\left(8 v, \sigma_{1}^{2}\right)$. In a similar way, if the expectation of the average speed for the autonomous vehicle is $\mathrm{w}$, the expectation for the maximum distance after 8 hours is $8 \mathrm{w}$ and the Gaussian is $N_{2}\left(8 w, \sigma_{2}^{2}\right)$. The total distance is given by a sum of Gaussians: $N\left(8 v+8 w, \sigma_{1}^{2}+\sigma_{2}^{2}\right)$. The probability of reachability is obtained by integration of the Gaussian (numeric method).

An important issue, however, is the lack of models for an estimation of the parameters of the Gaussians. While the average walking speed is speculative and depends on complex parameters, the standard deviation is linked to human variability. It is proposed here to look at marathon data [32]. Running a marathon and walking on Mars are very different activities, but the variability of the performance for the first activity, which can be expressed for example by a normalized standard deviation, provides an indication of the variability for the second. In 2010, for an average finishing time of 4 hours and 38 minutes, the standard deviation was 1 hour and 2 minutes, which represents $22.3 \%$ of the average speed. In this study, it is proposed to keep the same ratio to account for human variability. As regards the average speed of the vehicle, it strongly depends on the technical specifications that will be decided. For the Apollo mission, the lunar vehicle was able to reach $13 \mathrm{~km} / \mathrm{h}$. In a recent study, it was suggested that $25 \mathrm{~km} / \mathrm{h}$ would be an 
acceptable specification [33]. Though these speeds are relatively low, it is certainly possible to design faster vehicles if there are good reasons to do so. The greatest uncertainty comes from the terrain, which could be rough, rocky or sandy with the presence of obstacles. A comparable terrain, to a certain extent, has been encountered during the Dakar Rally, which occurred last year in the Arabic peninsula [34]. For that race, organizers tried to diversify the terrain, sometimes rocky, sometimes sandy, and potentially with unexpected obstacles that have to be skirted. The average speed of all stages was $110 \mathrm{~km} / \mathrm{h}$ and the standard deviation was 16.4 . In practice, the average speed and standard deviation values should be calculated according to the power of the vehicle and a detailed analysis of the landing site. For a first study, in order to take the variability of the terrain into account, it is proposed to use the Dakar standard deviation to average speed ratio, which is $14.9 \%$. Based on these assumptions, the only unknown parameters of the Gaussians are the average walking speed and the average speed of the vehicle. Two simulations are proposed with different values:

a) Optimized: Assuming an efficient mitigation of $0 \mathrm{~g}$ effects, an adaptation of the spacesuit for walking and a relatively fast vehicle, the average walking speed is around $3 \mathrm{~km} / \mathrm{h}$ (walking at $4 \mathrm{~km} / \mathrm{h}$ and making short stops) and the average speed of the vehicle is $20 \mathrm{~km} / \mathrm{h}$.

b) Pessimistic: It is assumed that the astronauts cannot walk and the vehicle has the same speed limit as the lunar rover of the Apollo mission $(\mathrm{v}=0 \mathrm{~km} / \mathrm{h}$ and $\mathrm{w}=13 \mathrm{~km} / \mathrm{h})$.

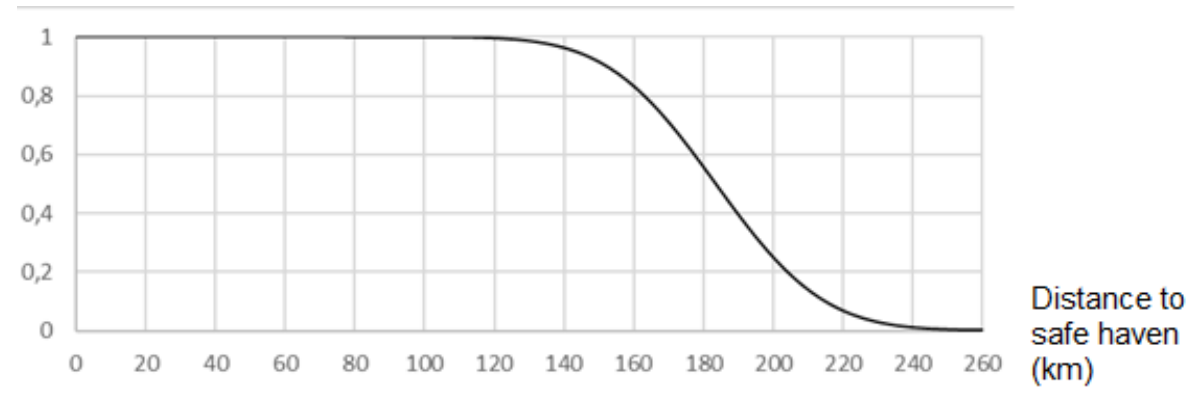

Fig. 5. Probability of reachability as a function of the total distance for case a) (optimized).

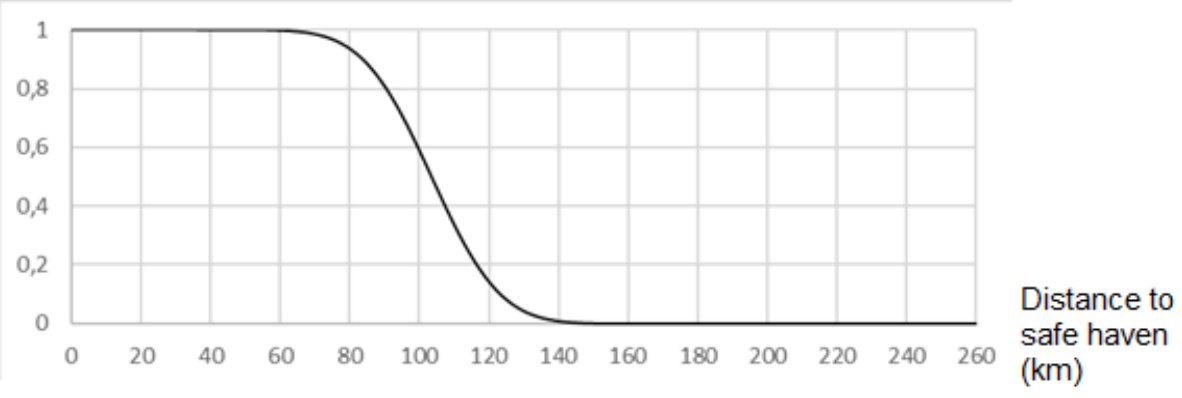

Fig. 6. Probability of reachability as a function of the total distance for case b).

Results are presented Fig. 5 and 6 . The probability of reachability greatly depends on the capacity of the autonomous vehicle and on the type of terrain between the astronaut and the base. As the proposed risk analysis does not take accidents, insurmountable obstacles and other difficulties into account (e.g., communication problems), the probability of success is certainly lower. It does however provide a first insight into the risk. This result is interesting for two reasons - first, because in most situations, the landing site would not be that far from the base and secondly, the mass penalty for such a rescue system would be acceptable.

\section{Conclusion}

A rescue system has been proposed to reduce the risk of crew loss during the descent and landing phase of a human mission to Mars. It is based on an ejection seat for each astronaut, a parachute and a small propulsion system for the landing on the surface. For a successful rescue, the astronauts must wear a spacesuit with full life support and surface 
rovers must be present on the surface with automatic driving abilities to reach them, provide complementary life support and transport them back to the habitable module. Special attention must be paid to interface design and astronaut training so that the astronaut is able to evaluate the available options effectively.

Finally, the proposed study for the rescue on the surface after an emergency landing is linked with the more general problem of rescuing astronauts in operations on the surface. The problem has already been addressed by NASA and the recommendation was to constrain the EVA team to operate within rescue range of the outpost [27]. If there is a single pressurised and several unpressurised rovers, the rescue range is the maximum reachable distance of the vehicle with less capacity. In our study, however, the strongest constraint is not the distance, but the time to reach the astronaut and the capacity of automatic systems to drive vehicles in rough terrain with numerous obstacles. This capacity has to be analysed in detail for a better understanding of the risks.

\section{References}

[1] R.D. Braun and R.M. Manning, Mars Entry, Descent and Landing Challenges, Journal of Spacecraft and Rockets, Vol. 44 (2), 310-323, Mar-Apr, 2007.

[2] J.A. Christian, K. Manyapu, G.W. Wells, J.M. Lafleur, A.M. Verges and R.D Braun, Sizing of an Entry, Descent, and Landing System for Human Mars Exploration, Journal of Spacecraft and Rockets, Vol. 45, No. 1, pp. 130-141, Jan-Feb, 2008.

[3] J. Cruz, A. Cianciolo, R. Powell, L. Simonsen, R. Tolson. Entry, descent, and landing technology concept trade study for increasing payload mass to the surface of Mars. 4th International Symposium on Atmospheric Reentry Vehicles and Systems, Arcachon, France, 2005.

[4] J. Connelly, H. Thronson, B. Drake, C. Carberry, R. Zucker, report of the Fifth Community Workshop on Achievability and Sustainability of Human Exploration of Mars (AM V Report), Washington DC (USA), 5-7 December 2017.

[5] H. Price, J. Cassady and G. Merril, Sortie-Class Human Missions to Mars, proceedings of the 42nd COSPAR Scientific Assembly, Pasadena (California, USA), ref. B4.2-26-18, 14-22 July 2018.

[6] D. R. Komar P. V. Tartabini, and J.R. Clark, Lunar and Mars Ascent and Descent/Entry Crew Abort Modes for the Hercules Single-Stage Reusable Vehicle, Technical Report, NASA Langley Research Center, NASA/TM-2018$219839,2018$.

[7] H. A. Ray Jr. and F. T. Burns. Development and Qualification of Gemini Escape System, NASA-TN-D-4031, June 1967. NASA Manned Spacecraft Center, Houston, TX, 1967.

[8] J. Colrat, H. P. Nguyen and H. Hirsch (1988). Hermes Escape System. Proceedings of the Int. Symp. on Europe in Space: Manned Space Systems, Strasbourg, France, April 25-29, 1988, ESA-SP-277. ESA, Noordwijk, The Netherlands

[9] D. J. Shayler, Space Rescue, Springer Praxis Books, January 2009.

[10] A.M. Kurzun, G. F. Dubos, C.K. Iwata, B.A. Stahl, A concept for the entry, descent, and landing of high-mass payloads at Mars, Acta Astronautica, vol. 66, p. 1146-1159, 2010.

[11] B. G. Drake, ed., Reference Mission Version 3.0 Addendum to the Human Exploration of Mars: The Reference Mission of the NASA Mars Exploration Study Team - EX13-98-036 - Exploration Office, NASA Johnson Space Center, June, 1998.

[12] J.M. Salotti, Revised Scenario for Human Missions to Mars, Acta Astronautica, vol. 81, p. 273-287, 2012.

[13] G. Genta, J.-M. Salotti and A. Dupas, IAA Study Group 3.16: Cosmic Study on Global Human Mars System Missions Exploration. Proceedings of the 66th International Astronautical Congress, IAC-15-A5.2, Jerusalem, 12-16 October 2015.

[14] B.G. Drake ed., Mars Architecture Steering Group, Human Exploration of Mars, Design Reference Architecture 5.0, 1st Addendum, NASA Johnson Space Center, 2009.

[15] J.M. Salotti, Robust, affordable, semi-direct Mars mission, Acta Astronautica, Volume 127, OctoberNovember 2016, pages 235-248, 2016.

[16] R. Zubrin and D. A. Baker, Mars Direct: Humans to the Red Planet by 1999, proceedings of the 41 st Congress of the International Astronautical Federation, 1990.

[17] A.A. Wolf, J. Tooley, S. Ploen, M. Ivanov, B. Acikmese, K. Gromov, Performance trades for Mars pinpoint landing, proc. of the IEEE Aerospace Conference, Big Sky, Montana (USA), 2006.

[18] M. Braddock M, Artificial gravity: small steps on the journey to the giant leap. J Space Explor 6: 137-145, 2017.

[19] Mr. Kenneth, S. Thomas, Mr. Harold, J. McMann, US Spacesuits, Chichester, UK, Praxis Publishing Ltd., 2006. 
[20] A. F. J. Abercromby et al, Crew Health and Performance Extravehicular Activity Roadmap: 2020, NASA Langley Research Center, NASA/TP-20205007604, 2020.

[21] B. Pitts, Astronaut Bio-Suit for Exploration Class Missions, MIT Man-vehicle lab, NIAC Phase I Report, 2001.

[22] Cavagna, G., Willems, P. \& Heglund, N. Walking on Mars. Nature 393, 636 (1998). https://doi.org/10.1038/31374

[23] Apollo 11, The NASA mission reports, vol. 2, Apogee Books, 1999.

[24] P. Heather, G. Alptekin, M. Cates, C. Bernal, M. Dubovik, Y. Gershanovich, "Development of a Rapid Cycling $\mathrm{CO} 2$ and H2O Removal Sorbent", proceedings of the 37th International Conference on Environmental Systems, 2007.

[25] S.M.C. Lee, L.C. Ribeiro, S.S. Laurie, A.H. Feiveson, V.V. Kitov, I.S. Kofman, B.R. Macias, M. Rosenberg, I.V. Rukavishnikov, E.S. Tomilovskaya, J.J. Bloomberg, I.B. Kozlovskaya, M.F. Reschke and M.B. Stenger, "Efficacy of Gradient Compression Garments in the Hours After Long-Duration Spaceflight”, Frontiers in physiology, 2020.

[26] A. P. Porter, B. Marchesini, I. Potryasilova, E. Rossetto and D. J. Newman, "Soft Exoskeleton Knee Prototype for Advanced Space Suits and Planetary Exploration," 2020 IEEE Aerospace Conference, Big Sky, MT, USA, 2020, pp. 1-13, doi: 10.1109/AERO47225.2020.9172373.

[27] S.J. Hoffman, ed., The Mars Surface Reference Mission: A Description of Human and Robotic Surface Activities, NASA/TP-2001-209371, 2001.

[28] J.M. Salotti, C. Laithier, B. Machut, A. Marie, A. Bruneau, G. Grömer, B. H. Foing, Small rover exploration capabilities, Advances in Space Research, vol. 55, pp. 2484-2491, 2015.

[29] J.R. Sklar, Modern HF Signal Detection and Direction Finding, MIT Lincoln Laboratory Series, The MIT Press, Cambridge (Massachusetts), 2018.

[30] S. Clark, InSight tweaks trajectory to home in on Mars landing site, Spaceflight Now, November 2018.

[31] NASA, Mars InSight Launch Press Kit, May 2018, NASA JPL reports, access: (https://www.jpl.nasa.gov/news/press_kits/insight/launch/download/mars_insight_launch_presskit.pdf).

[32] Staff of the Marathon Guide website, 2010 USA Marathon Statistics and Report: Available at: http://www.marathonguide.com/Features/Articles/2010RecapOverview.cfm

[33] M. Baratta, G. Genta, D. Laurenzano and D. Misul, Exploring the surface of the Moon or of Mars What kind of ground vehicles are required? Proc. Of the $9^{\text {th }}$ IAA Symposium on the Future of Space Exploration, Towards the Moon Village and Beyond, Torino, Italy, June 27-29, 2017.

[34] Dakar Rally Official Website, accessed May 2021, available at: https://www.dakar.com/en/rankings 